\title{
What is this thing we do?
}

\author{
Wendy Lawson \\ Whitecliffe Placement, Co-ordinator, New Zealand
}

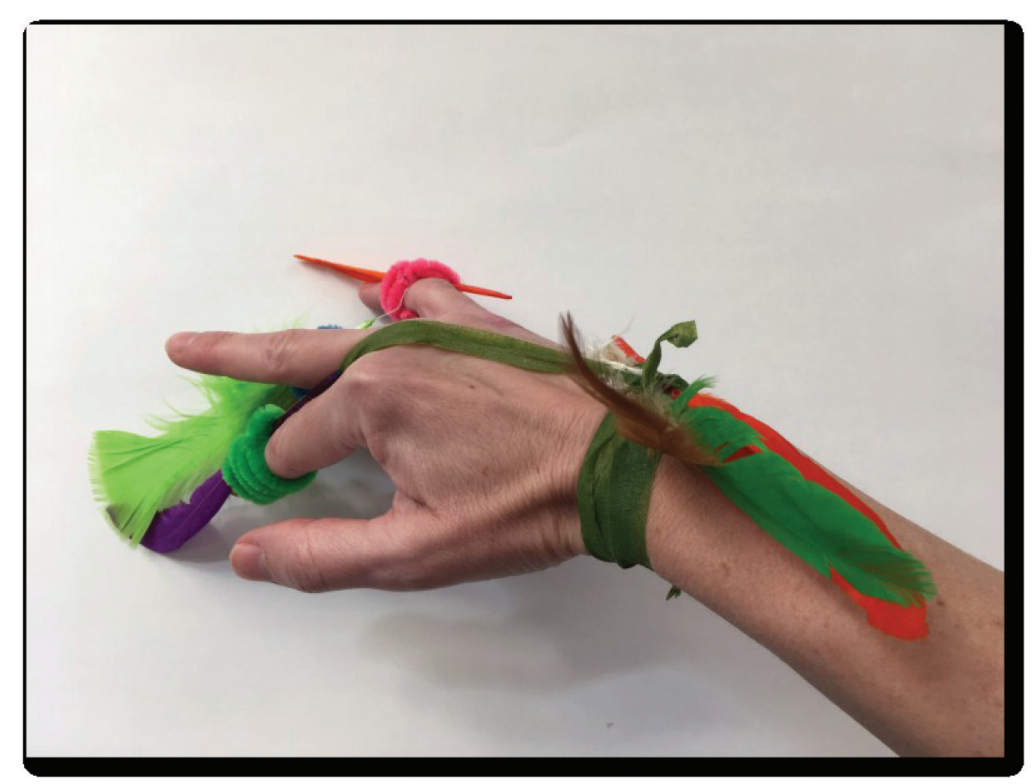

FEATHER ONE | Breathing

\section{What is this thing we do?}

It is leaning into a lamppost.

Slipping into a crevice.

Sinking into the trunk of a tree.

We are carriers, tree sap perhaps.

Moving through spaces,

Taking in air and pushing out breath.

There is supplenessand a stretch, Catching feathers as they fall, tugging and

Being tugged,

By the thread that links us all. 


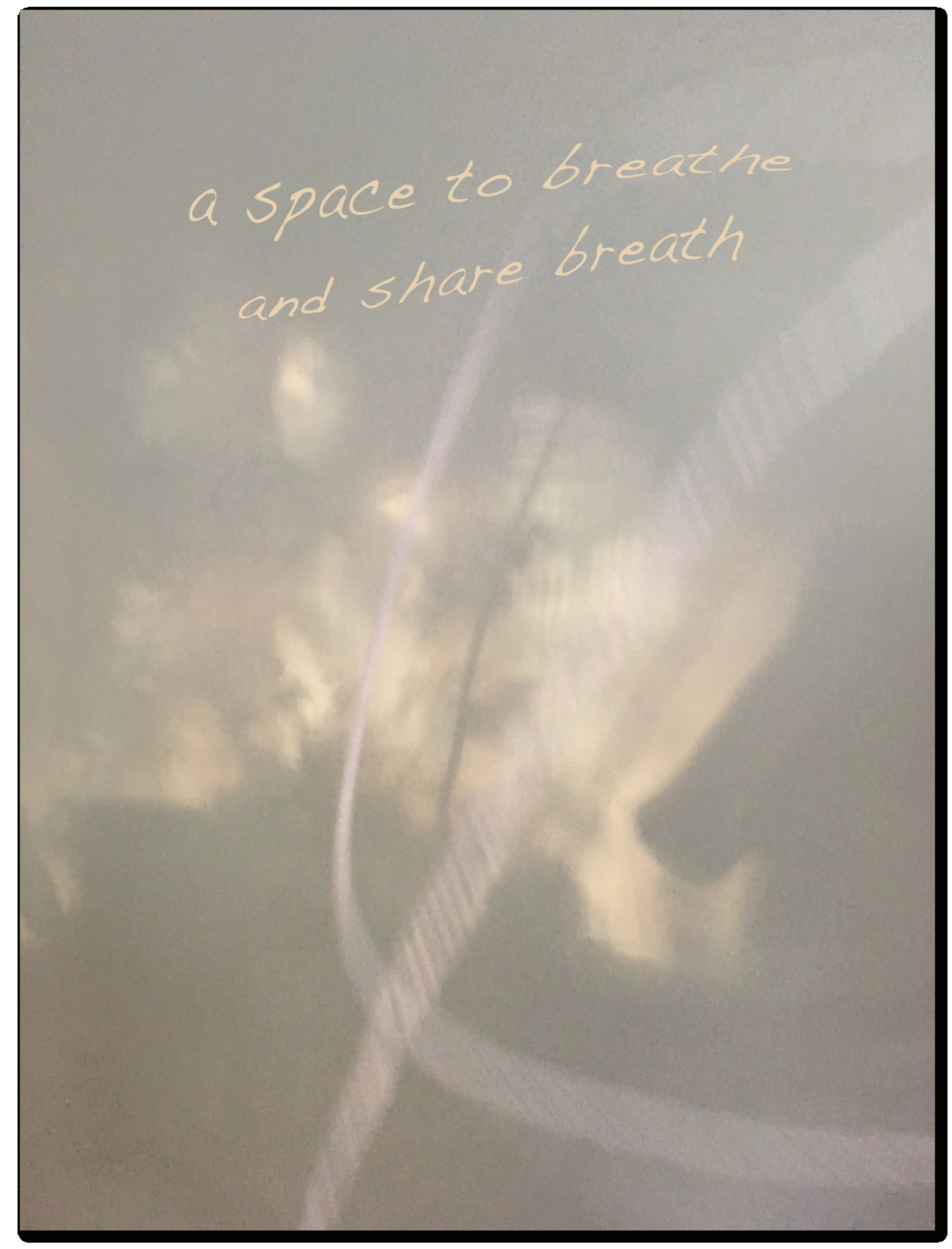

FEATHER TWO | A breathable space 


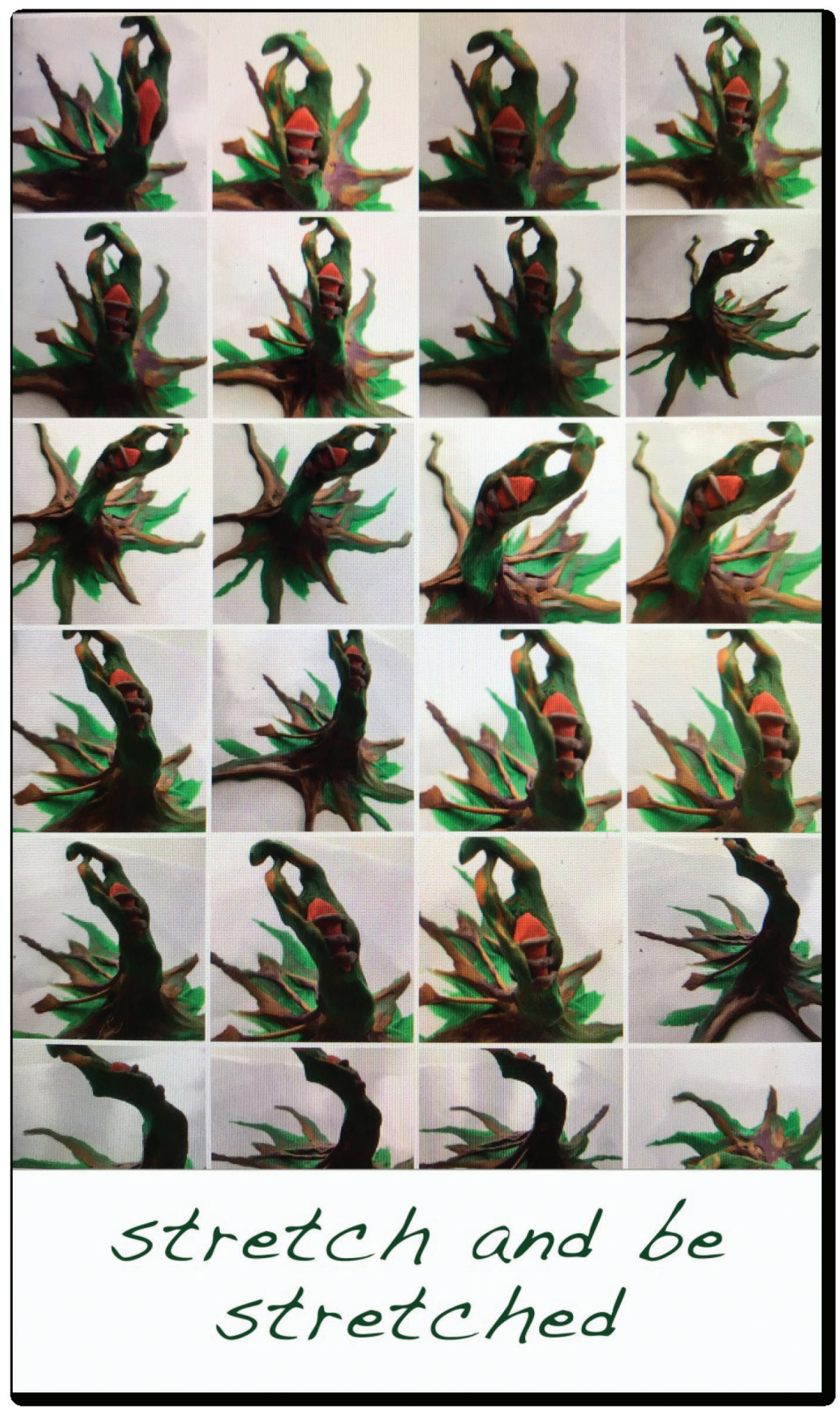

FEATHER THREE | Stretch 


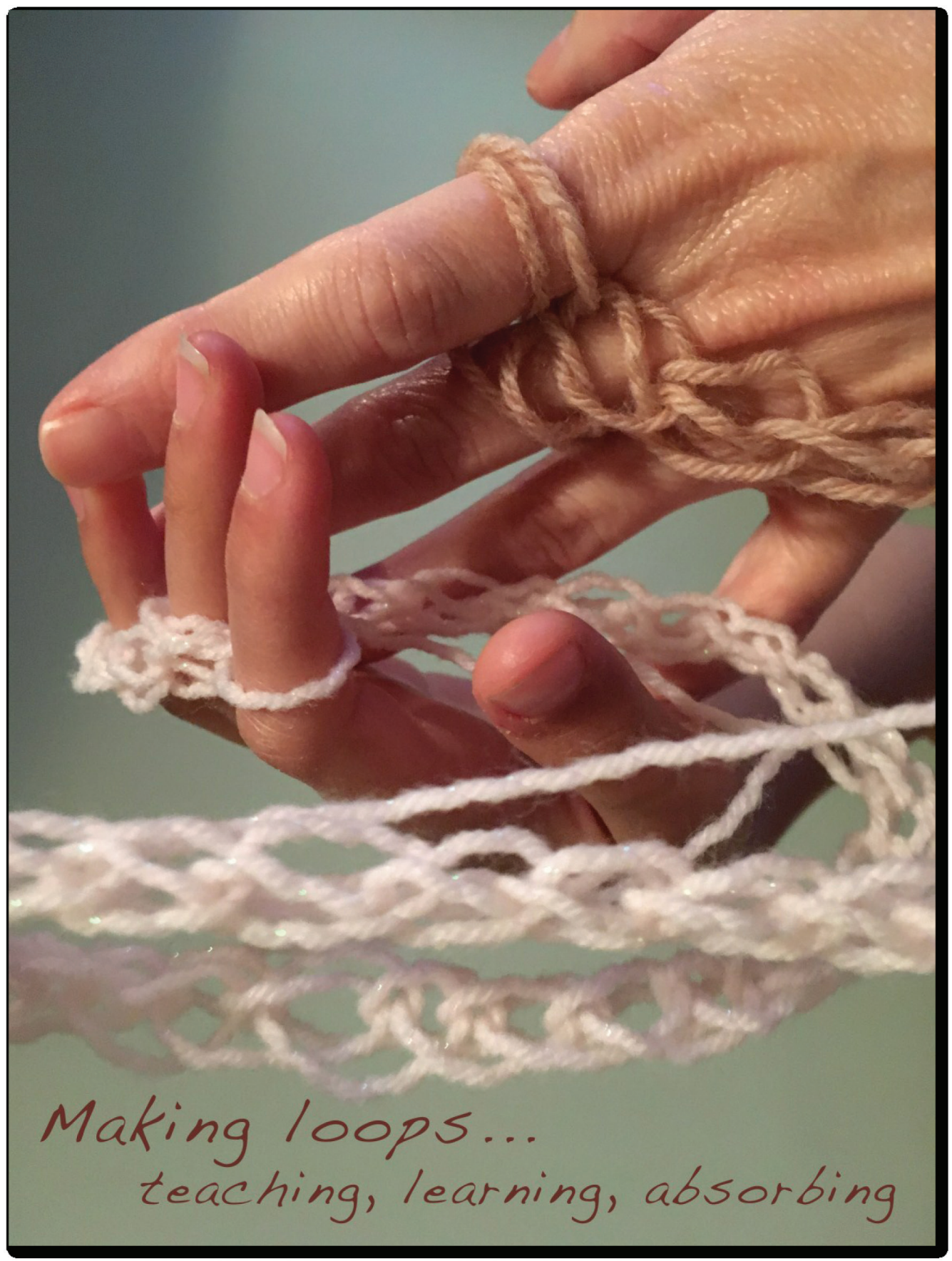

FEATHER FOUR | Making Loops 


\section{Tenderness}




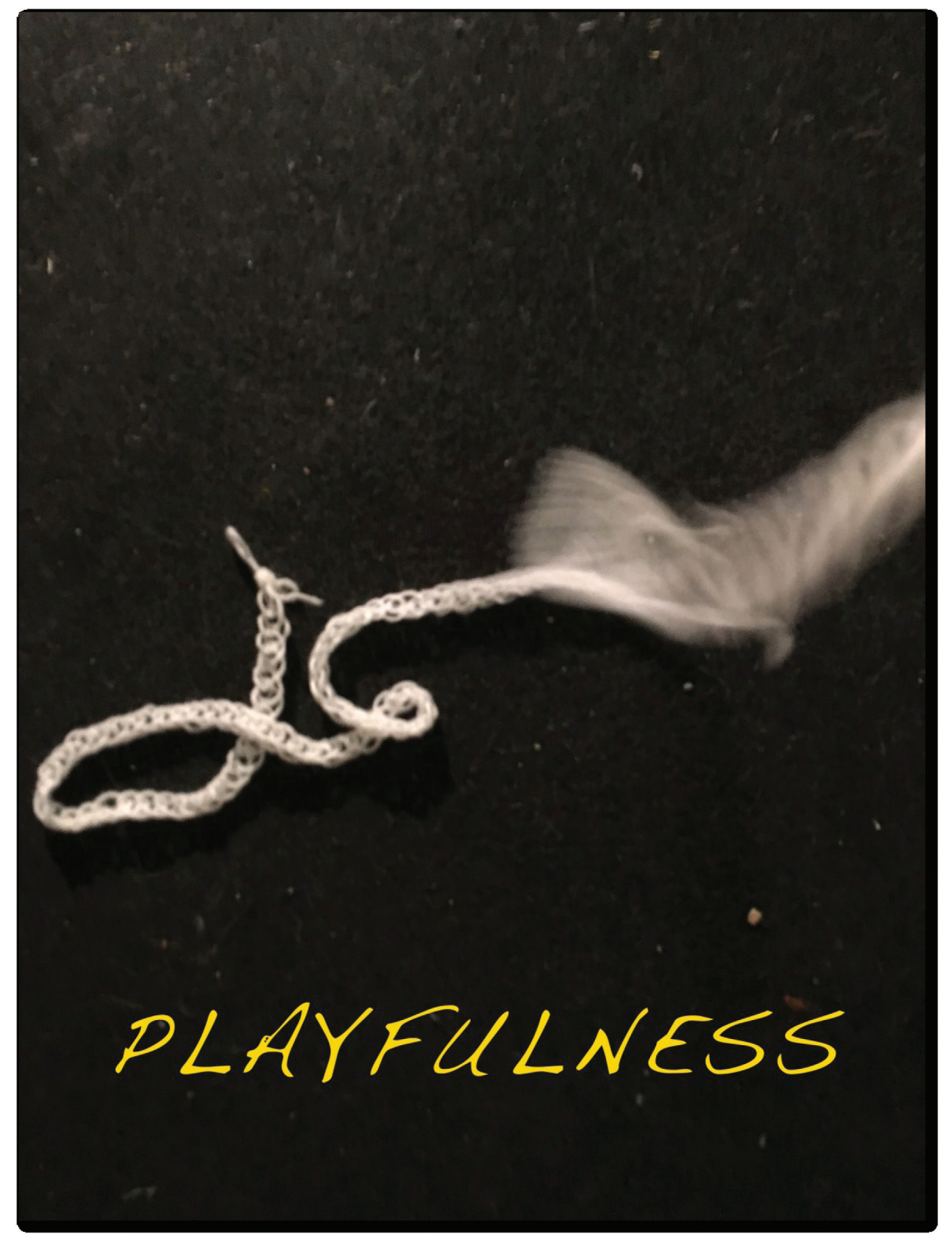

FEATHER SIX | Playfulness 


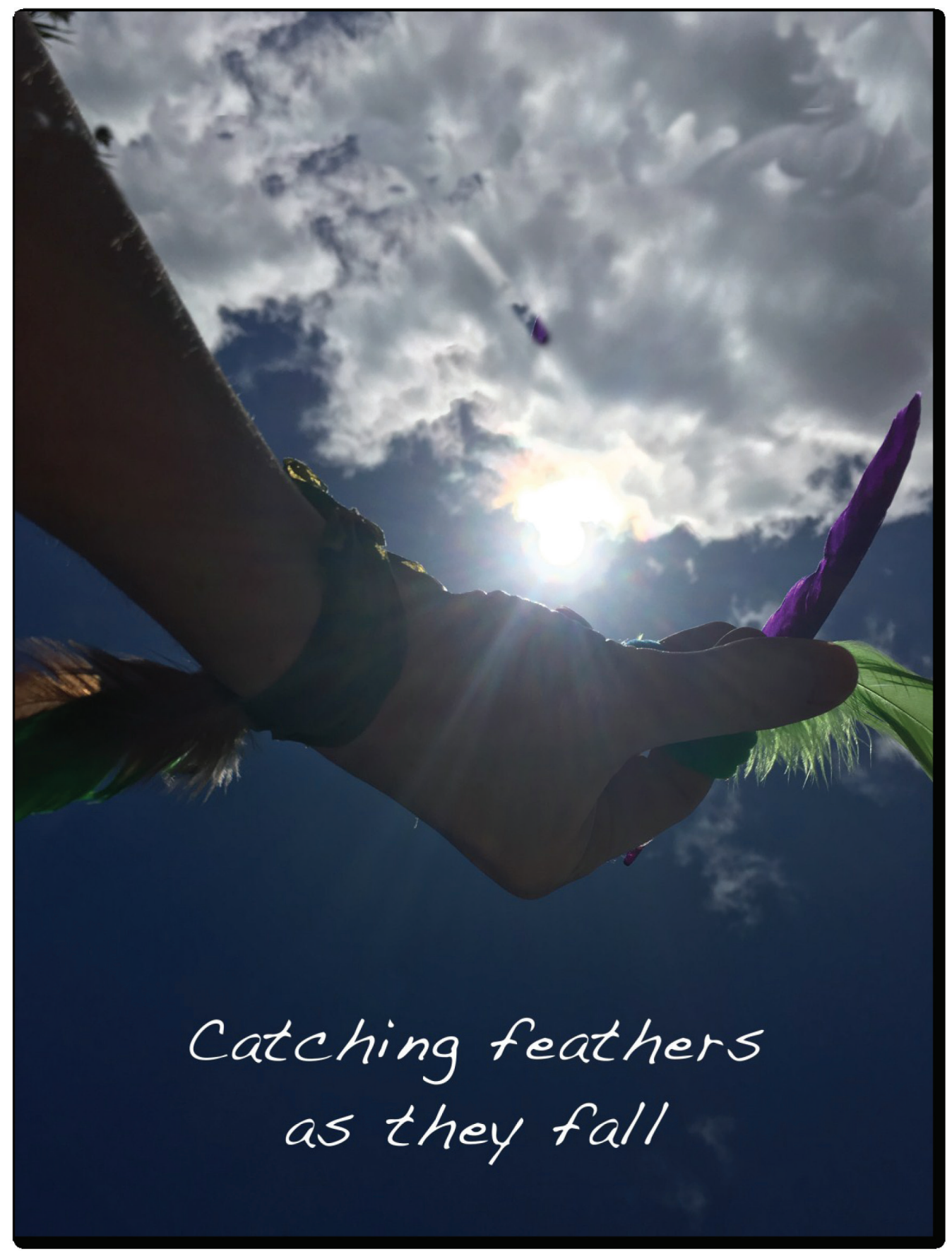

FEATHER SEVEN | Catching feathers 


\section{About the Author}

Wendy Lawson BFA(Hons), MAAT(Clinical)(Hons), AThR is a practicing artist, arts therapist and creative spirit. Before studying arts therapy at Auckland's Whitecliffe College of Arts and Design Wendy travelled extensively and worked across diverse environments including ICT, health and disability, the arts, youth, and education. She has a growing community engagement focus and is involved with the ongoing development of Whitecliffe's arts therapy programmes. 